\title{
Long-term prognosis of duodenal ulcer: follow-up study and survey of doctors' estimates
}

\author{
J GREIBE， P BUGGE， T GJøRUP， T LAURITZEN， O BONNEVIE， H R WULFF
}

British Medical fournal, 1977, 2, 1572-1574

\begin{abstract}
Summary
In 1976 we reviewed a randomly selected cohort of 227 patients with duodenal ulcer first diagnosed in 1963 . The cohort comprised cases diagnosed in both hospitals and general practice. Fifty patients had died, 12 had emigrated, and $154(93 \%)$ of the remaining patients were interviewed. Fifty-seven medically treated patients had no symptoms, 44 had mild symptoms, and 19 had more severe symptoms. The remaining 34 patients had been treated surgically. Cases diagnosed in hospital had a more severe prognosis than those diagnosed in general practice.

A random sample of 65 general practitioners and 78 medical and surgical gastroenterologists tried to predict the results of this study. The range of the predictions was very wide showing that individual prognostic estimates were highly unreliable. The mean prediction by all doctors differed little from the actual result, suggesting that the collective experience of the medical profession is more reliable. The predictions of general practitioners, physicians, and surgeons showed small systematic differences, presumably reflecting the different types of patients they treat.
\end{abstract}

\section{Introduction}

Most studies of the prognosis of patients with duodenal ulcer have been confined to those in hospital. Only Fry ${ }^{1}$ studied unselected patients seen in his general practice and found that the disease was remarkably benign: no more than $5^{\circ}{ }_{0}$ of patients had severe symptoms after ten years and only $16^{\circ}{ }_{0}$ had been treated surgically.

Knowledge of the true prognosis of duodenal ulcer is imperative since it may determine the advice given to patients by their doctors, particularly whether or not they recommend surgical treatment. We set out to assess the long-term outcome in Danish patients with duodenal ulcer and to compare our findings with the expectations of general practitioners and gastroenterologists.

\section{Material and methods}

Almost all barium-meal examinations of residents of the County of Copenhagen are done at three hospitals. As part of a larger epidemiological study ${ }^{23}$ a search through the hospitals' records gave a sample of men and women found to have radiological evidence of duodenal disease for the first time in 1963 . The $x$-ray reports were reviewed, and all patients included in the study had either a duodenal

\footnotetext{
Medical Department C, Herlev University Hospital, 2730 Herlev Copenhagen, Denmark

J GREIBE, CAND MED, registrar

P BUGGE, medical student

$T$ GJØRUP, medical student

T LAURITZEN, medical student

O BONNEVIE, CAND MED, senior registrar

$\mathrm{H}$ R WULFF, MD, consultant physician
}

crater or deformity of the duodenal cap (the latter finding was accepted only in patients who had not undergone biliary tract surgery).

A total of 227 randomly selected patients were subsequently traced through the National Register in March 1976. Those who had not died or emigrated were invited to attend for an interview. Those unable to attend were interviewed by telephone. Information was collected about the clinical course (including operations and complications), but particular attention was paid to the symptoms of the medically treated patients during the preceding 12 months-whether they suffered no ulcer symptoms, mild symptoms (which did not interfere with their daily work), or moderate or severe symptoms (which at some time during that year had interfered with their daily activities).

Before starting the interviews we sent letters to a random sample of 100 members of the Danish College of General Practitioners and 100 members of the Danish Society of Gastroenterology (including both hospital-employed medical and surgical gastroenterologists). They were asked to predict the proportion of the interviewed patients they would expect to have been treated surgically for duodenal ulcer (including acute operations) and the proportion who had been completely symptom-free during the preceding 12 months without operation; how many had suffered mild symptoms; and how many had suffered moderate or severe symptoms. Sixty-five general practitioners and 78 gastroenterologists answered the questionnaires.

\section{Results}

The total sample of patients with duodenal ulcer comprised 152 $(67 \%)$ men and $75(33 \%)$ women. Their median age (range 15-86 years) was 49 years at the time of diagnosis. Of the patients, $67 \%$ had been referred to the $x$-ray departments as outpatients by general practitioners (and very few specialists) and $33 \%$ were hospital patients. These were all inpatients as the hospitals at that time had no medical outpatient departments. In $118(52 \%)$ a crater had been found, and $109(48 \%)$ had deformity of the duodenal cap but no visible crater.

Fifty patients $(22 \%)$ had died during the follow-up period of 13 years (table I), but a life-table analysis showed that this mortality was not significantly higher than expected in the population of the County of Copenhagen. There were more deaths among hospital patients (26 of 75) than among general-practice patients $(24$ of 152) $(P<0.01$; $\gamma^{2}$ test), but this was not related to the sex of the patients or to the radiological findings at diagnosis. Twelve people had emigrated, and of the remaining $165,154(93 \%)$ were interviewed.

TABLE I-Total number of patients with radiological evidence of duodenal ulcer in 1963 selected for follow-up in 1976, and number available for interview

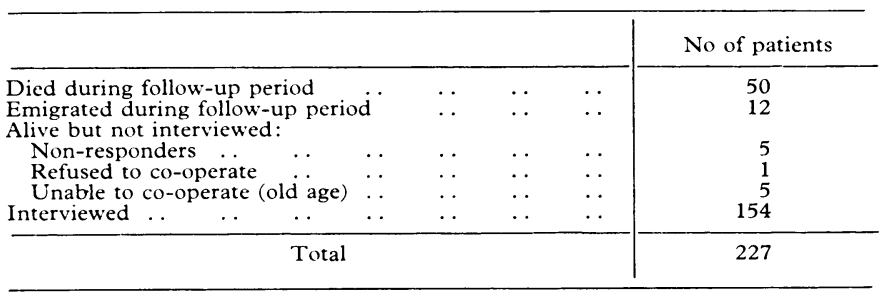

The main results of the interviews are summarised in table II. Medically treated patients were asked about the severity of their symptoms during the preceding 12 months - that is, very nearly the 13 th year after diagnosis. Fifty-seven of the medically treated patients had no symptoms, and of these, approximately three-quarters said they had been symptom-free for more than five years; approximately half said they had been symptom-free for more than 11 years. Only 19 patients still had moderate or severe symptoms. Thirty-four patients 
TABLE II-Patients with duodenal ulcer diagnosed in 1963: results of interviews after 13 years, showing severity of symptoms of medically treated patients and number of patients treated surgically

\begin{tabular}{|c|c|c|}
\hline Outcome & $\begin{array}{l}\text { No }\left({ }^{0}{ }_{0}\right) \text { of } \\
\text { patients }\end{array}$ & $\begin{array}{l}95^{\circ} \text { o confidence } \\
\text { limits }\end{array}$ \\
\hline $\begin{array}{l}\text { Medical treatment: } \\
\text { No symptoms } \\
\text { Mild symptoms } \\
\text { Moderate or severe symptoms } \\
\text { Surgical treatment }\end{array}$ & $\begin{array}{l}57(37) \\
44(29) \\
19(12) \\
34(22)\end{array}$ & $\begin{array}{r}29-45 \\
22-37 \\
7-19 \\
15-30\end{array}$ \\
\hline Total & $154(100)$ & \\
\hline
\end{tabular}
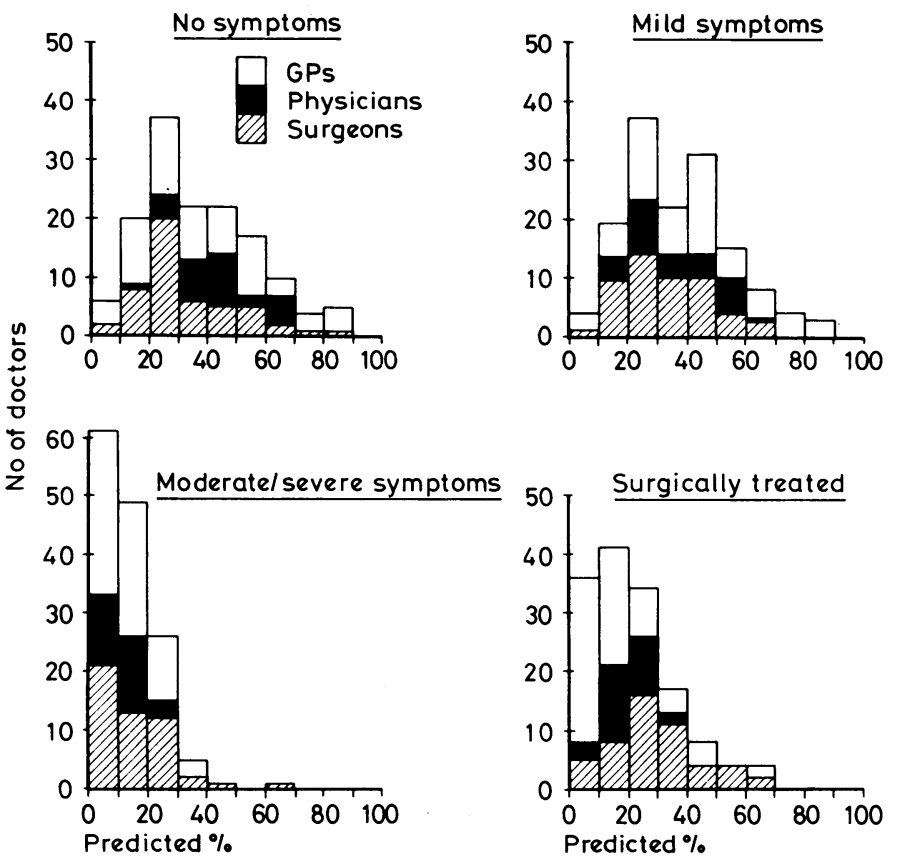

Doctors' predictions of results of follow-up study: proportions of medicall treated patients predicted to have no symptoms; mild symptoms; moderate or severe symptoms; and proportion predicted to have had surgical treatment.

had been treated surgically, including two emergency operations for acute haemorrhage and six for perforation and other complications.

Table III shows the results of the interviews according to sex, radiological finding at diagnosis, and method of referral. The incidence of surgical treatment was significantly higher in patients with a crater than in patients with deformity of the duodenal cap, and higher in hospital cases than in general-practice cases $\left(\mathbf{P}<0.05 ; \chi^{2}\right.$ tests; $\mathrm{DF}=1$ ). No other statistical differences were found (using the $\chi^{2}$ test and the Mann-Whitney test, assuming that the four prognostic subgroups constituted an ordinal scale). Thirty interviewed patients $(20 \%)$ had had bleeding episodes during the 13 years, and the incidence was similar among those whose $x$-ray films had originally shown a crater $(17 \%$ ) and those who had presented with only deformity of the duodenal cap $(22 \%)$.

\section{DOCTORS' ESTIMATES}

The great variation in the doctors' predictions of the result of the follow-up study is shown in the figure. Predictions of the proportion treated surgically ranged from $1 \%$ to $66 \%$. The predicted proportions of medically treated patients with no symptoms or mild symptoms showed a similar variation, whereas doctors generally agreed that only few medically treated patients would have severe symptoms after 13 years. There was no obvious correlation between the predictions and the seniority of the doctors.

Nevertheless, the mean values of the doctors' predictions came remarkably close to the actual result of the follow-up study (table IV). The surgeons predicted a larger proportion of surgically treated patients than the physicians and general practitioners (a tendency which is also apparent in the figure) but otherwise there was little difference between the groups of doctors. Statistically the results of the follow-up study were compatible with the mean predictions of all doctors $(P>0.60)$ and the mean predictions of physicians $(P>0.20)$ and surgeons $(P>0 \cdot 20)$, but not with the mean predictions of the general practitioners $(P<0.05)\left(\chi^{2}\right.$ test for goodness of fit; $\left.D F=3\right)$.

\section{Discussion}

Patients with a disease such as duodenal ulcer present a varied clinical range, from those not seeking medical advice to those seen in general practice and in hospital. ${ }^{4}$ Most research is done on hospital patients; this may give misleading results, since most patients with this disease are treated in general practice. In this study patients whose diagnosis was first made during a hospital admission had a more serious prognosis than those first diagnosed in general practice. More "hospital" patients had died and proportionately more had been treated surgically.

The prediction of the individual doctor was a very imprecise measure of the actual prognosis owing to the mutual disagreement among the doctors. The mean prediction, however, proved very accurate, though small differences were found between the predictions of different categories of doctors, presumably reflecting that general practitioners, physicians, and surgeons treat patients from different parts of the disease range.

Most of the interviewed patients had no symptoms or very mild symptoms, and, like Fry, ${ }^{1}$ we concluded that duodenal ulcer disease shows a definite trend towards cure or long-term

TABLE III-Long-term outcome in patients with duodenal ulcer according to sex, $x$-ray finding at diagnosis, and method of referral

\begin{tabular}{|c|c|c|c|c|c|c|}
\hline Group & $\operatorname{Men}(\%)$ & Women $(\%)$ & Crater $\left({ }^{0}{ }_{0}\right)$ & Deformity $(0)$ & $\begin{array}{c}\text { General-practice } \\
\text { cases }(\%)\end{array}$ & $\begin{array}{l}\text { Hospital } \\
\text { cases }(\%)\end{array}$ \\
\hline $\begin{array}{l}\text { Medically treated patients: } \\
\text { No symptoms } \\
\text { Mild symptoms } \\
\text { Moderate or severe symptoms } \\
\text { Surgically treated patients }\end{array}$ & $\begin{array}{l}37(37) \\
30(30) \\
9(9) \\
25(25)\end{array}$ & $\begin{array}{l}20(38) \\
14(26) \\
10(19) \\
9(17)\end{array}$ & $\begin{array}{l}26(34) \\
17(22) \\
11(15) \\
22(29)\end{array}$ & $\begin{array}{r}31(40) \\
27(35) \\
8(10) \\
12(15)\end{array}$ & $\begin{array}{l}46(40) \\
32(28) \\
16(14) \\
21(18)\end{array}$ & $\begin{aligned} 11(28) \\
12(31) \\
3(8) \\
13(33)\end{aligned}$ \\
\hline Total & $101(101)$ & $53(100)$ & $76(100)$ & $78(100)$ & $115(100)$ & $39(100)$ \\
\hline
\end{tabular}

TABLE IV-Mean values of doctors' predictions compared with actual results of follow-up study. Figures are percentages of patients

\begin{tabular}{|c|c|c|c|c|c|}
\hline & $\begin{array}{c}\text { GPs } \\
(\mathbf{n}=65)\end{array}$ & $\begin{array}{c}\text { Physicians } \\
(\mathrm{n}=28)\end{array}$ & $\underset{(n=50)}{\text { Surgeons }}$ & $\underset{(n=143)}{\text { All doctors }}$ & Follow-up study \\
\hline $\begin{array}{l}\text { Medically treated patients: } \\
\text { No symptoms } \\
\text { Mild symptoms } \\
\text { Moderate or severe symptoms } \\
\text { Surgically treated patients }\end{array}$ & $\begin{array}{l}36 \\
38 \\
11 \\
15\end{array}$ & $\begin{array}{l}40 \\
33 \\
10 \\
17\end{array}$ & $\begin{array}{l}30 \\
30 \\
13 \\
27\end{array}$ & $\begin{array}{l}35 \\
35 \\
11 \\
20\end{array}$ & $\begin{array}{l}37 \\
29 \\
12 \\
22\end{array}$ \\
\hline
\end{tabular}


symptomatic improvement. This trend probably reflects the spontaneous course of the disease, as medical treatment (diet, antacids, and anticholinergics) has had no convincing effect in controlled studies. ${ }^{5-7}$ The introduction of the $\mathrm{H}_{2}$-receptor antagonist cimetidine has greatly altered the prospects of medical treatment, as short-term treatment with this drug promotes ulcer healing and symptomatic remission, ${ }^{8}$ and the efficacy of long-term treatment is being investigated. Our results are important in this context as they suggest that most patients with duodenal ulcer will need only intermittent or continuous cimetidine treatment for a limited period.

The overall mortality of the patients in this study was not significantly higher than that of the general population, but this was because of the relatively small number of patients. The cohort studied was part of a larger sample of 1475 patients with duodenal ulcer forming the basis of an epidemiological study which showed a significant excess mortality during the first one or two years after diagnosis. The increased mortality in that study was confined to the cases diagnosed during an admission to hospital. ${ }^{9}$

Bleeding episodes had occurred equally often among patients who had a crater at the time of diagnosis and those who had only deformity of the duodenal cap. This observation suggests that deformity alone is a reliable sign of duodenal ulcer disease, and the higher incidence of surgical treatment among patients with a crater may simply imply that before the introduction of duodenoscopy surgeons were more reluctant to operate on patients whose ulcer had not been shown by barium-meal examination.

This study has wider implications, as the higher degree of accuracy of the mean predictions may suggest that the collective experience of the medical profession is reliable, though differences in the experience of individual doctors cause prognosis to be less precise. All clinical decision-making depends on predictions, which are often based on uncontrolled experience and not on results of clinical research, and it might prove valuable to study the precision and accuracy of doctors' prognostic estimates in other diseases.

\section{References}

${ }^{1}$ Fry, J, British Medical fournal, 1964, 2, 809.

2 Bonnevie, O, Scandinavian fournal of Gastroenterology, 1975, 10, 231.

${ }^{3}$ Bonnevie, O, Scandinavian fournal of Gastroenterology, 1975, 10, 385.

4 Wulff, H R, Rational Diagnosis and Treatment. Oxford, Blackwell, 1976.

5 Buchman, E, et al, Gastroenterology, 1969, 56, 1016

${ }^{6}$ Kaye, M E, et al, Gut, 1970, 11, 559.

' Sturdevant, R A L, et al, Gastroenterology, 1977, 72, 1.

${ }^{8}$ British Medical fournal, 1976, 2, 1975.

9 Bonnevie, O, Ugeskrift for Laeger, in press.

\title{
Decreased tuftsin concentrations in patients who have undergone splenectomy
}

\author{
ZVI SPIRER, VERA ZAKUTH, SAMUEL DIAMANT, W MONDORF, T STEFANESCU, \\ YITZHAK STABINSKY, MATI FRIDKIN
}

British Medical fournal, 1977, 2, 1574-1576

\begin{abstract}
Summary
Serum tuftsin concentrations were measured, using a radioimmunoassay developed in Israel, in normal subjects and in patients who had undergone splenectomy. Concentrations in those who had undergone traumatic and elective splenectomy were much lower. The tuftsin concentration in 38 patients with Hodgkin's disease who had undergone splenectomy during staging laparotomy was not significantly different from the mean concentration in other patients who had had elective splenectomy. In four patients who underwent splenectomy for non-malignant haematological disorders measurements
\end{abstract}

\footnotetext{
Paediatrics Department A, Municipal-Governmental Centre, Tel Aviv, Israel

ZVI SPIRER, MD, physician

VERA ZAKUTH, MSC, scientist

SAMUEL DIAMANT, MD, physician
Zentrum der Innern Medizin der Johann Wolfgang Goethe Univers- ität, Frankfurt am Main, West Germany
W MONDORF, MD, physician
T STEFANESCU, MD, physician

Department of Organic Chemistry, Weizmann Institute of Science, Rehovot, Israel

YITZHAK STABINSKY, MSC, scientist

MATI FRIDKIN, PHD, scientist
}

made before and after operation showed that tuftsin concentrations fell significantly in the days after operation.

The increased susceptibility to overwhelming infections of patients with Hodgkin's disease and others who have undergone splenectomy may be related to the low tuftsin concentrations. As pre-splenectomy tuftsin concentrations in patients with Hodgkin's disease were normal, the practice of performing staging laparotomy and splenectomy in patients with Hodgkin's disease should perhaps be reconsidered.

\section{Introduction}

Fulminant bacterial infections are now widely accepted to be a serious complication after splenectomy. ${ }^{1-6}$ But the incidence of sepsis in patients who have undergone elective splenectomy seems to differ from that in those who have had their spleens removed because of abdominal trauma with rupture of the spleen. ${ }^{5}$ Splenectomy has detrimental consequences because of the spleen's function in maintaining defence mechanisms against bacteria. The spleen plays a particularly important part in controlling the phagocytic capacity of polymorphonuclear leucocytes, and Najiar et al have found defective phagocytosis in the leucocytes of humans and animals who have undergone splenectomy. They attributed this defect to the absence of tuftsin, ${ }^{8}$ a basic tetrapeptide produced in the spleen that acts as a phagocytosis-stimulating agent of both polymorphonuclear leucocytes and macrophages. ${ }^{9}$

Tuftsin has recently been synthesised, ${ }^{1011}$ and the biological 